\title{
Removing the "Hermetic Seal" from the Aquatic Ape Hypothesis: Waterside Hypotheses of Human Evolution
}

\author{
Algis V. Kuliukas \\ University of Western Australia, Perth, Australia \\ Email: algis.kuliukas@uwa.edu.au \\ Received 26 April 2014; revised 21 May 2014; accepted 15 June 2014 \\ Copyright (C 2014 by author and Scientific Research Publishing Inc. \\ This work is licensed under the Creative Commons Attribution International License (CC BY). \\ http://creativecommons.org/licenses/by/4.0/

(c) (i) Open Access

\begin{abstract}
The current (March/April 2014) issue of Evolutionary Anthropology is rare in that it contains two papers specifically critiquing the so-called "aquatic ape hypothesis" (abbreviated "AAH", but better labelled, in the plural, "waterside hypotheses of human evolution."). The first (Foley \& Lahr, 2014) is a general assessment of the authors' interpretation of the AAH and the second (Rae \& Koppe, 2014) is a particular rebuttal of one specific idea-the sinuses for floatation hypothesis. This short paper is a response to both. It is argued that the first uses a straw man's argument to characterize the so-called "AAH" as arguing for exclusively more aquatic adaptations than waterside proponents have in the past. Foley \& Lahr's paper is also unscholarly in that it does not draw upon the latest scholarly work. One chapter of that work re-defines and re-labels the "AAH", which was of key importance to their paper. Rae \& Koppe's paper is harder to criticize but still contains some problems which the authors overlook in their strict rejection of the sinuses for floatation hypothesis. If one understands that waterside hypotheses of human evolution are simply postulating that major phenotypic differences between humans and chimps are the result of a (perhaps slight) differential in the selection from wading, swimming and diving, they cannot be ridiculed as belonging in the same "crazy box" as creationism as Henry Gee recently argued and must take their place within mainstream physical anthropology.
\end{abstract}

\section{Keywords}

AAH, Aquatic Ape Hypothesis, Waterside Hypotheses, Paranasal Sinuses

\section{Introduction}

The current (March/April 2014) issue of Evolutionary Anthropology is refreshingly rare, in the peer reviewed 
specialist literature pertaining to human evolution, in that it contains two papers specifically about the so-called “aquatic ape hypothesis.” As I have studied this idea and its reception in mainstream anthropology to PhD level for the past 15 years, I was very interested to read them.

The first, “The Role of 'the Aquatic' in Human Evolution: Constraining the Aquatic Ape Hypothesis” (Foley \& Lahr, 2014), seems primarily concerned with distinguishing “water stuff” (p. 57); things that the authors argue can legitimately be studied by mainstream anthropology, with what one can only presume is characterized as "crazy stuff”, all those random aspects of human physiology that "aquatic ape” proponents go on about as evidence of a more aquatic past: ideas that Henry Gee recently publicly dumped in the same category as creationism (Gee, 2013)—a suggestion the authors concluded was “probably a reasonable position” (p. 56).

The second, “Sinuses and Flotation: Does the Aquatic Ape Theory Hold Water?” (Rae \& Koppe, 2014), is focused on one specific waterside hypothesis - that human paranasal sinuses may be explained as floatation devices. The idea is rejected. As the authors put it, "we can cross flotation off the list of proposals demanding investigation" (p. 63). Both papers seem to have been written in response to the recent publicity generated by a symposium about human evolution in London in May 2013, presented by Sir David Attenborough, and organized by Dr. Peter Rhys Evans of The Royal Marsden Hospital (2013). This was the same event that prompted Henry Gee to write his remarkably vitriolic outburst, tarring more aquatic ideas with the creationist brush. Dr. Evans had presented his ideas (Rhŷs Evans, 1992) at the conference on the paranasal sinuses and so Rae \& Koppe’s paper, in rejecting that idea, added further relevance.

\section{Foley \& Lahr}

A key difference between the two approaches is apparent. The later paper reported that proponents of waterside hypotheses of human evolution had moved on from the early Hardy/Morgan formulation. It was pointed out that “... the AAT is no longer one idea; several variations on the initial concept exist, including the idea that all apes have 'aquarboreal' ancestors” (p. 60). The first paper, however, repeatedly got this muddled. It latched onto arguments from quite different ideas and reported them as if they were contradictions of the same single model, characterizing the "aquatic ape" with "enormous adaptability", that it "has been able to move chronologically from the Miocene to the Middle Pleistocene, as well as from the ocean to the beach” (p. 59). For example, a key argument of the paper is that care should be taken to distinguish between evidence for waterside life (which the authors agree is not controversial at all) and other aspects which “... emphasizes adaptations to deep water (or at least underwater) conditions” (p. 58). It was the "right side” (those pertaining to deep water physical adaptations) of both their figures ( 1 and 2 ) that was reserved for the "AAT" and not the rest, it was repeatedly argued.

This argument is basically a straw man, the same basic technique John Langdon used in the last attempt to "critique” the “AAH” in a first class anthropological journal, 17 years ago (Langdon, 1997). Any idea can be ridiculed if it is exaggerated. There is little evidence that Alister Hardy ever proposed that man was as aquatic as most aquaskeptics seem to think he did. Hardy wrote "I am imagining this happening in the warmer parts of the world, in the tropical seas where Man could stand being in the water for relatively long periods, that is, several hours at a stretch" (Hardy, 1960: p. 642) and Elaine Morgan certainly did not think in such extreme terms as proposed by the authors here (Morgan, 2005).

The Foley \& Lahr paper, like Langdon's, can also be criticized for being unscholarly. Langdon mentioned but did not draw upon, the, as then, recent proceedings of the Valkenburg Symposium (Roede et al., 1991). Credit should go to Rae \& Koppe here for at least mentioning Langdon's critique and pointing out that a counter critique had been made (Kuliukas, 2011). Foley \& Lahr failed to do so. Worse still, in my opinion, is that the authors gave as much, if not more, credence ("a thorough examination of the evidence” p. 57) to a layman's journalistic web site (Moore, 2005), one that is not at all peer reviewed, to the latest scholarly work ("a recent AAH summary” p. 59) largely written by professional scientists. This work, "Was Man More Aquatic in the Past? Fifty Years after Alister Hardy: Waterside Hypothesis of Human Evolution”, was thus mentioned and listed in the references but, like Langdon with Roede et al. before, was not drawn upon at all. In their case they omitted to cite the key chapter in that volume specifically written to describe the various "more aquatic" scenarios and to clearly re-label and define an umbrella term for them.

"Waterside hypotheses of human evolution assert that selection from wading, swimming and diving and procurement of food from aquatic habitats have significantly affected the evolution of the lineage leading to Homo sapiens as distinct from that leading to Pan” (Kuliukas \& Morgan, 2011). 
This definition makes clear that the confusion and controversy surrounding these ideas is no longer justified. If one remembers a lesson from Population Genetics 101-that for selection to overcome drift, it need only be greater than the reciprocal of twice the effective population size—one should understand that if there was even the slightest difference in the amount of wading, swimming and diving done by human ancestors, as compared to those of the chimps and gorillas, one would expect to see quite profound phenotypic differences between the two lineages in remarkably short evolutionary time scales. Despite Foley \& Lahr's efforts, there is no need for "constraining" the (singular) "aquatic ape hypothesis" because they (plural) have been redefined. No one is, or has ever been, arguing for mermaids here.

\section{Rae \& Koppe}

The second paper is more challenging to critique as it is fairer in its portrayal of the idea to which it contradicts. It is also more scientific in that it tries to identify a simple test of the hypothesis and then reports on some evidence pertaining to that test. Rae \& Koppe correctly identify the essential point of this particular waterside hypothesis as defined above.

"Although some current AAT exponents have shifted the locus of the (now semi-)aquatic phase of hominin evolution to the period immediately before the last common ancestor of all Hominoidea, the traditional and most often repeated anatomical traits cited in support of AAT are those differences seen between extant Homo sapiens and Pan: bipedalism, reduced body hair, a descended larynx, and larger brains." (my emphasis).

They continue... "If the same criterion is applied to sinuses, as implied by their invocation as flotation devices, the prediction follows that we, as a species, should exhibit more pneumatisation (a larger number of sinuses or an increase in their relative size) than do our closest living relatives; if we needed buoyancy and they did not, the number or size of our air spaces should have increased" (p. 61.)

With the caveat that one might challenge that it is not the number of sinuses that would necessarily be expected to increase, but the overall buoyancy they would impart, this is a fair test of the "sinuses for buoyancy" hypothesis.

Although their dismissal of the "first hypothesis" (the number of sinuses) is, I argue, a red herring, the evidence they offer for the second (their volume) deserves a response.

To reject this hypothesis the authors cited their paper (Rae \& Koppe, 2000). That study supported the null hypothesis that there was no significant change in the degree of pneumatisation among the hominoidae, but it should be noted that this study only considered the maxillary sinus. It also did not consider buoyancy specifically, but compared the volume of the maxillary sinus against the overall volume (but not mass, or density) of the skull. It is possible that other sinuses are relatively bigger in humans than chimps and/or that chimp skulls, being more robust, are less buoyant despite having larger sinuses.

Furthermore, although the authors were quite correct to identify that the proper test of this particular waterside hypothesis was to compare the sinuses of humans and chimpanzees, they then forgot this premise for the rest of the paper which draws upon a wide range of mammals (some aquatic and some not) in order to show that there is no correlation between the degree of aquatic lifestyle and the nature of their paranasal sinuses. Indeed they make the point that some aquatic mammals have lost them altogether.

To make such an argument would be to repeat the straw man of Langdon and Foley \& Lahr. If the hypothesis is that human ancestors simply did a little more wading, swimming and diving than chimp ancestors, then one would not predict their paranasal sinuses to converge with those of Cetacea or even Lutra, or Myocastor.

\section{Conclusion}

At the end of the day, the "sinuses for buoyancy" hypothesis has never been a major pillar of the mislabeled "aquatic ape theory". There are far more significant phenotypic differences between humans and chimpanzees that waterside proponents argue as stronger candidates of evidence of a more aquatic past, as Rae and Koppe noted themselves (see above). These include bipedalism (in waist deep water, extant apes are compelled to move, and continue to move, bipedally without forelimb support), the evolution of the human body hair pattern (swimming face down in coastal shallows, is a clear cut scenario to define the typical human body hair pattern), increased infant adipocity (as a buoyancy aid to help parents rescue infants in near-drowning situations) and the descended larynx and voluntary breath control—essential pre-requisite of speech (swimming and diving both provide a convenient scenario for this essential pre-requisite to have evolved). 
It is easy to sneer at such ideas and neither paper completely resisted the urge to do so, but one must seriously ask: If waterside hypotheses are not helpful in explaining such human traits, which ideas are? What exactly is the "mainstream" explanation for bipedalism, nakedness, infant adipocity and improved breath control and how are any of them better or any more plausible than simply postulating that humans were exposed to a little more selection from wading, swimming and diving than chimpanzees?

Rather than acting in a way that maintains the current situation of "two entirely parallel communities that essentially are hermetically sealed from each other” (Foley \& Lahr, 2014: p. 56) why aren’t physical anthropologists and evolutionary biologists actually doing more of the long-overdue science to test some of these fascinating ideas?

\section{References}

Foley, R. A., \& Lahr, M. M. (2014). The Role of "the Aquatic” in Human Evolution: Constraining the Aquatic Ape Hypothesis. Evolutionary Anthropology, 23, 56-59. http://dx.doi.org/10.1002/evan.21405

Gee, H. (2013). Aquatic Apes Are the Stuff of Creationism, Not Evolution. The Guardian Online, 7 May 2013. http://www.theguardian.com/science/occams-corner/2013/may/07/aquatic-apes-creationism-evolution

Hardy, A. (1960). Was Man More Aquatic in the Past? New Scientist, 7, 642-645.

Kuliukas, A. V. (2011). Langdon's Critique of the Aquatic Ape Hypothesis: It’s Final Refutation, or Just Another Misunderstanding? In: M. Vaneechoutte, M. Verhaegen, \& A. V. Kuliukas (Eds.), Was Man More Aquatic in the Past? Fifty Years after Alister Hardy: Waterside Hypothesis of Human Evolution. Bentham (Basel).

Kuliukas, A. V., \& Morgan, E. (2011). Aquatic Scenarios in the Thinking on Human Evolution: What Are They and How Do They Compare? In: M. Vaneechoutte, M. Verhaegen, \& A. V. Kuliukas (Eds.), Was Man More Aquatic in the Past? Fifty Years after Alister Hardy: Waterside Hypothesis of Human Evolution. Bentham (Basel).

Langdon, J. (1997). Umbrella Hypotheses and Parsimony in Human Evolution: A Critique of the Aquatic Ape Hypothesis. Journal of Human Evolution, 33, 479-494. http://dx.doi.org/10.1006/jhev.1997.0146

Moore, J. (2005). www.aquaticape.org

Morgan, E. (2005). Personal Comment. I Spent Many Hours Discussing These Matters with Her. We Co-Authored a Chapter Basically Trying to Clarify This Very Issue.

Rae, T. C., \& Koppe, T. (2000). Isometric Scaling of Maxillary Sinus Volume in Hominoids. Journal of Human Evolution, 38, 411-423. http://dx.doi.org/10.1006/jhev.1999.0357

Rae, T. C., \& Koppe, T. (2014). Sinuses and Flotation: Does the Aquatic Ape Theory Hold Water? Evolutionary Anthropology, 23, 60-64. http://dx.doi.org/10.1002/evan.21408

Rhŷs Evans, P. H. (1992). The Paranasal Sinuses and Other Enigmans: An Aquatic Evolutionary Theory. Journal of Laryngology Otology, 106, 214-225. http://dx.doi.org/10.1017/S0022215100119115

Roede, M., Wind, J., Patrick, J., \& Reynolds, V. (1991). Aquatic Ape: Fact of Fiction. Proceedings from the Valkenburg Conference, London: Souvenir Press.

Royal Marsden Hospital Conference (2013) Human Evolution Past, Present \& Future: Anthropological, Medical \& Nutritional Considerations. London, 8-9 May 2013. 
Scientific Research Publishing (SCIRP) is one of the largest Open Access journal publishers. It is currently publishing more than 200 open access, online, peer-reviewed journals covering a wide range of academic disciplines. SCIRP serves the worldwide academic communities and contributes to the progress and application of science with its publication.

Other selected journals from SCIRP are listed as below. Submit your manuscript to us via either submit@scirp.org or Online Submission Portal.
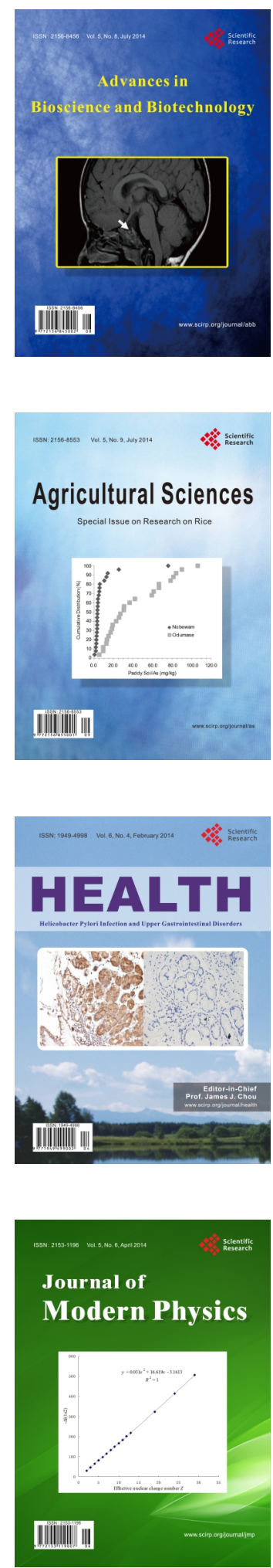
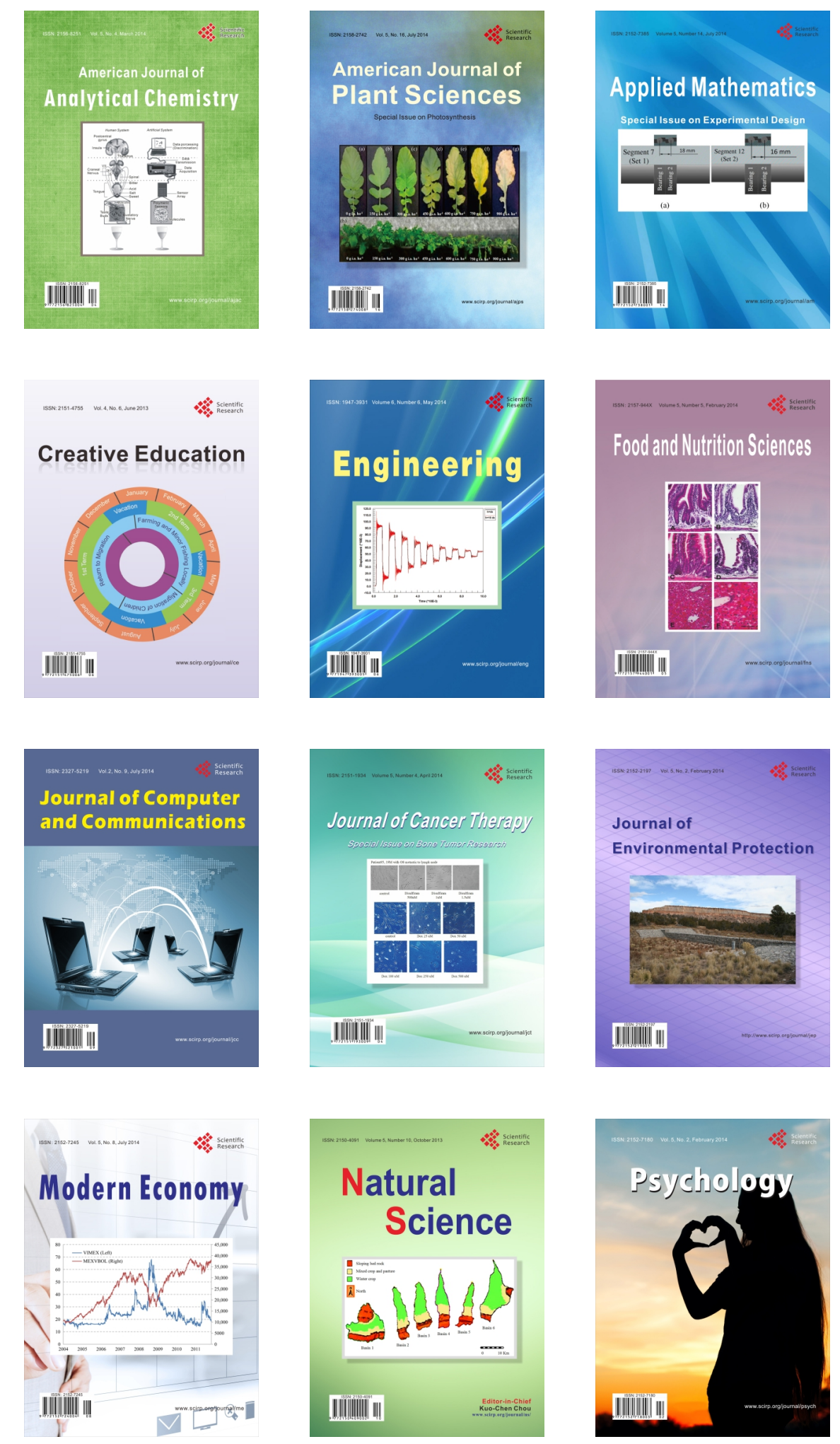